\title{
Correspondence
}

Journal of Medical Genetics 1989, 26, 216

\section{Absent or hypoplastic extraocular muscles?}

SIR,

I read with fascination the report 'Absence of a lateral rectus muscle associated with duplication of the chromosome segment 7q32 $\rightarrow$ q34' (Keith CG, Webb GC, Rogers JG. J Med Genet 1988;25:122-7).

Recent reports ${ }^{1-5}$ of extraocular muscle deficiencies of this nature have shown that there is almost always an extraocular muscle in the orbit, perhaps rudimentary or small, but that true absence may well be an extraordinarily rare event, if it ever does, in fact, occur in an absolute manner-especially in the presence of a relatively normal eye and orbital content as in this case.

Would the authors of this article advise us as to whether or not computerised tomography was carried out on this patient, and if so, was there evidence of a lateral rectus muscle in the orbit on the right side? If no such study was done, I would recommend that the authors obtain such a study, to define more accurately the abnormalities of this syndrome. A CT scan might even be useful in the management of the residual strabismus which the patient has. In the near future, in such cases, strabismus surgeons will be going back into the orbit and attaching prosthetic tendons from the globe to such rudimentary muscles. Such might even be attempted in the case reported, if an orbital muscle of reasonable dimension and location is found on CT scan.

$$
\begin{array}{r}
\text { PAUL E Romano } \\
\text { Department of Ophthalmology, } \\
\text { University of Florida, } \\
\text { College of Medicine, } \\
\text { Box J-284, } \\
\text { Gainesville, } \\
\text { Florida 32610-0284, USA. }
\end{array}
$$

${ }^{2}$ Mets MB, Parks MM, Freeley DA, Cornell FM. Congenit absence of the inferior rectus muscle: a report of three cases and their management. Binocular Vision 1987;2:77-86.

${ }^{3}$ Murphy BF, Annable WL. Congenital absence of the mediat rectus muscle with review of previous case reports. Binocular Vision 1987;2:87-92.

${ }^{4}$ Mather TR, Saunders RA. Congenital absence of the superio rectus muscle: a case report. J Pediatr Ophthalmol Strabism 1987;24:291-5.

5 Hansman ML, Peyster RG, Heiman-Patterson T, Greenfieidd VS. CT demonstration of extraocular muscle atrophy. J Comp@ Assist Tomogr 1988;12:49-51.

This letter was shown to Mr C G Keith, who replie as follows:

SIR,

We are grateful for Dr Romano's interest in our paper and for calling our attention to the usefulne of CT scanning for muscle detection in the orbite The child did have a CT scan of the brain and orbit? but unfortunately the slice level was set at $37.5 \mathrm{~mm}$, so only one slice was obtained through the orbit an it was not possible to determine from this wheth the muscle was in fact present. In view of the childs general condition it was not considered reasonable to repeat the CT scan and, since then, the child hos died. CT scanning has been used in our department routinely in checking for slipped or lost muscles ant it was used to show the absence of the lacrimal gland in a case of alacrimia. ${ }^{1}$ Dr Romano raises a ver important point and perhaps we should rename the paper 'Congenital non-attachment of the latera] rectus'.

\section{G KeITH \\ 231 Flemington RoaA, North Melbourns Victoria 305五: Australify}

\footnotetext{
References

${ }^{1}$ Romano PE. Editorial. More about how much more; congenital 'absence' or hypoplasia? Binocular Vision 1987;2:67-8.
}

\section{Reference}

1 Keith CG, Boldt DW. Congenital absence of the lacrimal glarked Am J Ophthalmol 1986;102:800-1. 